\title{
EL "EXITO" PARA LOS SABIOS DEL LIBRO DE LOS PROVERBIOS
}

1. CONTEXTO HISTORICO.

1.1. La Sabiduría Oriental.

Al iniciar el estudio del pensamiento sapiencial de Israel en "Proverbios", es necesario tener presente que ia sabiduría hebrea no constituyó un pensamiento aislado en el espacio. Por el contrario, en ella se observa una afinidad con la literatura sapiencial que floreció en todo el antiguo oriente de esa época.

Sabemos que los sabios israelitas fueron hombres abiertos al mundo que los rodeaba y al pensamiento de sus colegas extranjeros. Ellos mismos se encargaron de comun carlo al confesar su amor por los viajes:

"En medio de los grándes ejerce su servicio, $(x)$ ante los jefes aparece;

viaja por tierras extranjeras,

adquiere experiencia de lo bueno y lo malo entre los hombres" (Si 39,4)

Muchos son los estudiosos que se han preocupado de establecer paralelos entre la literatura sapiencial israelita y las de Mesopotamia y Egipto. En "Proverbios" han encontrado uno de los libros en que más claramente pueden establecer afinidades, tanto en la forma como en el contenido.

(x) (El escriba es a menudo funcionario, ministro, embaja dor). "La sabiduría de todos los antiguos rebusca" (Si 39, lc cfr. Qo 1, 16). 
En cuanto a la forma, H.G. Lambert establece una semejanza entre el comienzo de "Proverbios": 1,1-7 y el comienzo de las "Instrucciones de Amenemopé": 1, 1-12, de la sabiduria egipcia. Al igual, el llamado al "hijo" lo encontramos también en Amen. I1, 13 y en lo que queda de las "Enseñanzas de Shurrupak".

La presentación que predomina en las dos Coleccio nes Salomónicas, de "mashal" en disticos, se encuentra también en los. "Proverbios" o "Dictámenes populares" de Babilonia y demostrado por W.G.Lambert. A proposito de es ta misma forma citada, W. F. Albright dice que el mismō esquema se ha encontrado en los poemas de Ugarit.

En cuanto a la sernejanza en las ideas, el mismo. W. G. Lambert ha establecido algunas similitudes con la sabi duría Sumero-Acádica, resaltando sobre todo, el tema deT pobre, la protección que se les debe a ellos y a los desvalidos, preocupaciones frecuentes en Babilonia y posible mente proveniente de antiguos textos sumeros. En ambas obras, los sabios se preocupan de la retribución, es decir, castigar la injusticia y premiar la justicia; además coinciden en la preocupación de prevenir contra la mujer cortesana y en estimar la buena esposa como una fuente de agua:

"Bebe el agua de tu cisterna,

la que brota de tu poza" ( $\mathrm{Pr} .5,15 \mathrm{cfr}$. $\mathrm{Pr} .5,16-18$ )

En ambas literaturas se considera el trabajo fuente de riqueza: $\operatorname{Pr} .12,11 \mathrm{a}$ cfr. $\operatorname{Pr} .28,19 ; 12,24,27 ; 14$, 4 ; y la palabra de gran importancia.

"Adquirir sabiduría, cuánto mejor que el oro; adquirir inteligencia es preferible a la plata" ( $\mathrm{Pr}, 16,16)$

Sin embargo, a pesar de las coincidencias que se puede establecer entre ambas obras, se ha dicho que los es critos babilonios aparecen menos orientados hacia la enseñanza moral y menos religiosos que los proverbios biblicos.

H. Renard y B. Gemser han establecido, a su vez,pun tos de contacto con la sabiduría Asiria en lo que se re fiere a temas generales, lugares comunes a los sabios, a 
veces en textos precisos, pero aseguran que no es posible establecer un paralelo en cuanto a género literario, pues este es muy diferente en ambas obras.

Pero, la afinidad más grande de "Proverbios" se ha encontrado con la sabiduria egipcia. Relacionado con la reflexión religiosa en ambas obras hay coincidencia en lo que respecta al dominio de Dios en los acontecimientos: Pr. $161-9=$ Amen, $X I X, 11-17 /$ invitación a ponerse en sus manos: $\mathrm{Pr} .16,3,7,20$ y Amen.IX,5; XXIII,10/ Dios protege al justo y vigila al que le apoya: $\operatorname{Pr} .17,15 ; 15,29$; 20,22 y Amen.XXII, 1-8/ Ambos proclaman que es mejor la pobreza con Dios que la riqueza en la injusticia: Pr.15,16; 11,28 y. Amen IX, 5; XVI, 12-14.

Relacionado con la sabiduría misma, las coincidencias son menos precisas y numerosas. En Egipto se encuen tra la oposición sabio-necio, ya que el escrito de sabiduría egipcia se dirige más al escriba, preocupado de la per fección del escrito que al sabio preocupado de la perfec = ción moral. Como en todo Oriente, tanto en Egipto como en Israel, el "centro" de la sabiduría es el "corazón" y hay que formarlo y disponerlo para ella; $\operatorname{Pr} .3,1 ; 4,4,21 \mathrm{~s}$; 15,14 y Pth 40s; Amen III, 11s; IX, 10; XX3s/ En ambos escritos el sabio es "el que escucha": $\operatorname{Pr} .12,15 ; 13,1 \mathrm{y}$ ' Ptah 534-550/ La sabiduría se adquiere dicen ambos: Pr. 22,$15 ; 20,11$ y Ptah 405. En cuanto a la moral familiar,am bos dan consejos para la elección de una esposa: $\operatorname{Pr}$. 18,22; 5,15-20 y Ptah 325-332. Alerta contra el adulterio: Pr. $2,16-19 ; 23,27-28$ y Ani III, 13-16.

En lo que se refiere a la relación padres-hijos, existe una notable diferencia entre el pensamiento egipcio e israelita. La Biblia se interesa en la educación de los hijos y Egipto sólo habla de educación cuando se refie re a la formación de los escribas. Egipto alaba sólo aT "hijo obediente": Ptah 565-575; 591-595; 197-205; en cambio en la Biblia se alaba tanto al hijo obediente como al "sabio": Pr. 23, 19-22;23,24-26;10,1; 15,20/ En gene ral, el sabio de "Proverbios" se preocupa de la educación de los hijos: $\mathrm{Pr} .23,13-14 ; 29,15,17,21$.

Respecto al projimo, ambas sabidurias son sensibles a la amistad: su valor en la Biblia: $\mathrm{Pr}$. $18,24,27,10$ y su elección en Ptah 464-470; caridad para con los indigentes: 
Pr. 19, 17 y Ptah 16,1s; Ani VIII,4; dar el bien por el mal: $\operatorname{Pr} .25,21 ; 17,13$ y Amén IV, 110; V,6.

Ambos pensamientos sapienciales tienen puntos comu nes respecto al juicio de la riqueza y la pobreza. Los sá bios condenan el deseo de riqueza y avaricia: $\operatorname{Pr} .28,20 \mathrm{~b}$, 22 y Ptah 298-320/ también critican el enriquecimiento rápido: $\operatorname{Pr}$. 13,11s y Ani VI, 5-10.

Tanto en la sabiduría egipcia como en la de Israel tienen origen real. Es un codigo de moral que se supone dirige un rey a su hijo para prepararlo en su sucesión: Pr. 31,1s y en Egipto "Las Instrucciones de Kheti III a su hijo Merikaré y de Amenemhat a su hijo Sesostris I; Pr. 25,6 y Ptah 220-229; Pr.23, 1-3; 6-8 y. Ptah 120-145; Pr. $16-15 ; 19,12 ; 20,2$ y Amen $x X, 8 \mathrm{~s}$.

Las coincidencias presentadas no significan en ca da caso un préstamo. Ya se dijo que en lo que respecta a las coincidencias Babilonias y Asirias fuera de las semejanzas parciales en cuanto a temas importantes, nada corresponde en el dominio acádico al libro de Proverbios, diverso en sus partes componentes y además más profundo. Con respecto a las semejanzas con la sabiduría egipcia, cuando las ideas se hacen más afines, el género literario es totalmente diferente.

Proverbios es, pues, un escrito con fisonomía propia, con una historia diferente $y$ en la que el sentimiento religioso y moral Jahvista de fondo, se afirma con el ti empo (1).

\subsection{Otros escritores biblicos}

Aparte de la influencia sapiencial, comán a todo el oriente, los sabios de Israel conocieron, por vía oral en un comienzo y más tarde por las colecciones escritas, a otros hombres que tuvieron sus mismas inquietudes. De esta manera $A$. Robert explica cierto parecido con Salmos, discursos proféticos y con la legislación deuteronomica, a la que debemos agregar, además, el parentesco con el Jahvista en Génesis 2-4, tanto por la analogía en el tema como en los motivos literarios. 
Es indudable que en la primera parte de "Proverbios", la más recientes cronologicamente y escrita hacia 480 a.C., los sabios reflejan en sus consejos al individuo las mismas preocupaciones religiosas y morales de los profetas y del deuteronomista. En esta colección Pr. 1-9 la sabiduría per sonificada habla como un profeta, exhorta en un tono profético semejante a Jeremías.

Hay, ademas, otros puntos en que se acercan estos es critores y se refieren al plan religioso, a la vida moral, estableciendo las contrapartidas entre justo y pecador; $r i-$ co y pobre; el problema de la retribución.

En el plan religioso: encontramos puntos de contacto entre Jr. 11,20; 20,12 y Pr. 17,$2 ; 21,2$ y Ps. $7,10 /$ tanto en Jeremías, salmistas y sabios coinciden en exaltar la felicidad del que se confía en Jahveh:

"El que está atento a la palabra encontrará la dicha, el que confía en Jahveh será feliz" (Pr. 16,20)

"Bendito sea aquel que fía en Jahveh, pues no desfraudará Jahveh su confianza" (Jr. 17,7)

"Dichoso el hombre aquel

que en Jahveh pone su confianza" (Ps。40,5)

En lo que se refiere a la vida moral, tanto sabios moralistas como profetas y salmistas hacen la oposición en tre justo y pecador:

"Justificar al malo y condenar al justo;

ambas cosas abomina Jahveh" (Pr. 17,15)

"Pues yo sé que son muchas vuestras rebeldias

y graves vuestros pecados,

opresores del justo, que aceptais soborno

$y$ atropelláis a los pobres en la Puerta" (Am. 5,12)

También se asemejan: $\operatorname{Pr} .17,23 ; 15,27 \mathrm{y}$ Is. 1,23;

Ez. 22,12 y PS 15,5 .

Todos ellos hace, además, oposición entre rico-pobre $y$ todos tienden a proteger a los débiles contra la exalta ción de los ricos: 


$$
\begin{aligned}
& \text { Pr. } 22,22 \text { - Am. } 5,15 \\
& \text { Pr. 24,11 - Ps.82, } \\
& \text { Pr. } 15,25 \text { - Dt.26,12; Ps. } 68,6
\end{aligned}
$$

Es preciso hacer notar que la riqueza se entiende con la justicia como el fin o meta normal de la Sabidu ría:

"Conmigo están la riqueza y la gloriá,

la fortuna solida y la justicia" (Pr.8,18)

"Hacienda y riquezas en su casa.

su justicia por siempre permanece". (Ps. 112,3 cfr. Dt.7,12s)

En 10 que respecta a la retribución, las coinciden cias son más en la idea que en Ta forma o palabras:

- Dios da a cada uno según sus obras:

"El da a cada hombre según sus obras" (Pr. 24,12d)

"Que tá al hombre pagas con arreglo a sus obras" (Ps. 62,13)

"Pues tambien a ellos los reducirán a servidumbre muchas naciones y reyes grandes, y les pagaré según sus obras y se gún la hechura de sus manos". (Jr. 25,14)

- El justo es bendecido por Dios: Pr. 10,6 - Ps.24,5

- No hay desgracia para el justo pues Jahveh lo libera de ella Pr. 12,1 - Ps. 91,10; Ps. 37,39s.

- El justo caerá pero se levantará:

"Que siete veces cae el justo, pero se levanta,

mientras los malos se hunden en la desgracia" (Pr. 24,16)

"Aunque caiga, no se queda postrado,

porque Jahveh la mano le sostiene" (Ps. 37, 24) $\mathrm{cfr} . \operatorname{Pr} .11,31$ y Ps. 37 completo; is. 3,11 y $\mathrm{Pr}, 11,31 \mathrm{~b}$.

- No hay que envidiar a los pecadores porque para ellos no hay mañana: $\operatorname{Pr} .3,31 ; 23,17 ; 24,1,19 ; \mathrm{Jr} .12,1$; Ps. 37,$15 ; 73,3$.

- A veces la retribución se presenta no como una in tervención divina.o de una sanción moral, sino más bien, 
como consecuencia natural de las cosas: $\operatorname{Pr} .22,8 a ; 0$ : $.8,7$; $\mathrm{Pr} .1118 \mathrm{~b}$ y $0 \mathrm{~s} .10,12 \mathrm{a}$. minos:

Además estos escritores coincidieron en algunos tér-

"Jahveh Dios hizo brotar del suelo toda clase de árboles

deleitosos a la vista y buenos para comer, y en medio

del jardín, el árbol de la vida" (Gén. 2,9)

"Es árbol de vida para los que a ella están asidos,

felices son los que la abrazan". (Pr. 3,18$)$

Comparación de la dulzura de las palabras o de la sa bidurla con la de la miel: Pr. 16,24; 24,13; Ez.3,3; PS.19,11. Son elementos de los que se valen los moralistas.

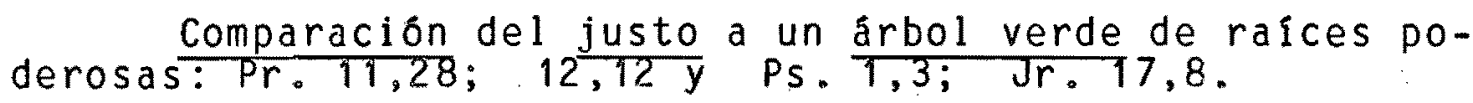

- Figuras como fuego, brasas para representar la actividad destructiva del malo, del mentiroso: $\mathrm{Pr}, 26,18 \mathrm{y}$ Is. 50,11 .

- Figuras como espada, cuchillo, flecha, para representar las fal+as de la lengua:

"gente cuyos dientes son espadas,

y sus mandibulas cuchillos," (Pr. 30,14)

"sus dientes son lanzas y saetas,

su lengau, una espada acerada".(Ps. 57, 5c)

Estos contactos entre los sabios de Israel, Salmis tas, profetas, el Jahvista y con los escritos deutoronómi cos, debieron establecerse oralmente en un comienzo, en tiempos anteriores al exilio, en lo que se refiere a la mayor parte de los proverbios de las dos colecciones Salomoni cas (2). 


\section{ANALISIS CRONOLOGICO}

2.1. Mentalidad y Método de los Sabios

Ya demostrada la múltiple influencia que recibieron los sabios de Israel, es necesario penetrar en su mentalidad, en su filosofía de la vida. Su preocupación mayor la constituyó el individuo y su destino, y no la colectividad. Es justamente en este aspecto donde difieren esencialmente de los demas escritores biblicos antes citados., ya que para éstos 10 más importante fue el futuro de su pueblo. Los sabios, en cambio, no mostraron demasiado interés en estar en los primeros lugares del estado o de la politica sino más bien en manejar, orientar y dirigir a reyes y grandes con su consejo para el Exito personal, sin preocuparse cen tralmente por el futuro mismo del pueblo:

"Un rey sabio aventa a los malos,

y hace pasar su rueda sobre ellos" (Pr. 20,26)

"El rey que juzga con verdad a los débiles,

asegura su trono para siempre" (Pr.29,14) También cfr. 16, $10-15 ; 20,8,28 ; 29,14$.

Tampoco mostraron demasiada inquietud por la historia y futuro de sid pueblo, ni se mostraron tan interesados en el culto. Siendo su preocupación dominante el destino del individuo, la retribución es para ellos de capital importancia. El horizonte del sabio es la vida humana cotidiana. Su sabiduría es humana y de orden pragmatico. Sus enseñanzas se centraban en el arte de bien vivir, de acomodarse al orden del universo. El sabio de los medios para ser feliz y prosperar en la tierra. Todos sus consejos están dirigidos a mostrar que la sabiduría lleva necesaria mente a la felicidad y la necedad lieva a la ruina: Pr.14, 24a; Pr.10,14b. Este es el fundamento de la doctrina sapiencial, puesto que el mundo está gobernado por un Dios sabio y justo: Pr. 16,11. La experiencia les demostrará lo contrario y esto lo expondrán en el libro de Job y Qohé let, quienes cuestionan la experiencia misma.

Sin embargo, esta mentalidad del sabio va a evolucio nar con el tiempo. Como un testimonio de la sabiduría is raelita de diversas épocas, Proverbios, desde su formulación oral presalomónica hasta los escritos del s. Va.C., 
nos mostrara una evolución tanto en su forma como en su pensamiento. De una sabiduria concreta y práctica que es en sus inicios, aun cuando no esta ajena la fe jahvis $\mathrm{ta}$

("La bendición de Jahveh es la que enriquece, y nada le añade el trabajo a que obliga" (Pr. 10,22; del mismo tiempo: $\operatorname{Pr}$. 15,33; 14,27; 19,23; 28,5; $29,13,25 b, 26))$

se transformara cada vez más en una ciencia del hombre que conllevara la preocupación de orientar su vida en un sentido que va más allá de la concepción material y temporal que podía tener el israelita medio:

"El me enseñaba y me decía:

Retén mis palabras en tu corazón,

guarda mis mandatos y vivirás". ( $\mathrm{Pr}$. 4,4; tambiên con el mis mo sentido: $\operatorname{Pr}: 1,1-5,20-33 ; 3,13-18$.

La variedad de preocupaciones de los sabios se amplía a través de los siglos; y ya en $\mathrm{Pr}$. I, que es el libro mas reciente, al coincidir con las inquietudes reli giosas y morales de los demas escritores bíblicos, ya citados anteriormente, su mensaje llega a ser más universal.

La evolución en la forma es fácil de apreciar. Cuan to mas antiguo o primitivo es el escrito, tanto más breve y simple es la forma. En cambio los más recientes, son verdaderos discursos. En las dos colecciones Salomónicas $(10-22,16)$ y $(25-29)$ está representado el mashal en su forma primitiva, son breves sentencias, generalmente de un solo distico. En las dos colecciones de Sabios, que son posteriores, se observa una ampliación en la fórmula de ex presión, al igual que en Palabras de Agur y Lemuel. En $10 \bar{s}$ Proverbios Numéricos (30, 15-33) el sabio añade a la máxi ma, un elemento nuevo que es el enigma, la comparación. ET epílogo (cap..31,10-31) es una composición poética más erudita, en forma de acróstico: Finalmente, en el prólogo del cap. 1 al 9, que es la parte mas reciente, se observa una serie de instrucciones o discursos didacticos interrum pidos en dos oportunidades por la prosopopeya de la Sa = biduría.

El metodo del sabio de Israel está basado en la experiencia. Es fruto de su vida, de lo que ha visto u 
oldo; tambiên de la experiencia ajena, pues como hombre es tudioso y viajero, conoce la sabiduria de otros pueblos:Si, 39,4; Q0 1,16.

Estos sabios no crearon teorias nuevas, no ilustraron el destino del individuo por medio de reflexiones fi losóficas a la manera de los griegos, sino que actuaron co mo pedagogos y moralistas enseñando lo que habian visto. Adoptan muchas veces, una ficción literaria (Job) y se presentan como el padre que aconseja a su hijo. Su método es racional y critico, incluso llega a criticar su propio logro que es la sabiduría.

2.2. Evolución del Pensamiento Sapiencial de Proverbios.

Se sabe que los Proverbios fuerón escritos en diver sas épocas, por lo tanto para apreciar la evolución deI pensamiento sapiencial, debemos establecer el orden cronologico en que éstos se escribieron.

Siguiendo la opinión de estudiosos como André Baruca, Luis Alonso Schökel y Gemser, las diferentes colec ciones de Proverbios quedarían ordenadas en el tiempo, como sigue:

I Los libros más antiguos serian las dos colecciones Sa: lomónicas. Los tres autores coinciden en datarlos posiblemente en la época de Salomön. Pero Gemser es más exacto, sitúa la reunión de esta colección un siglo y medio después de Salomón y además hace una subdivi. sión de cada colección.

La 1a. Colección de Salomôn, según Gemser, se divide en:

$\left.A^{\prime}\right)$ del cap. $10-15$

B') del cap. $16-22,16$

Libro II cap. $10-22,16$

La 2a. Colección Salomónica (Libro V - cap. 25-29), compilada por sabios al servicio del rey Ezequias, a 
rededor del año 700 a.C. fue dividida en:

$A^{\prime \prime)}$ cap. 25-27

B'') cap. $28-29$

Ademas de dividirlos cambia su orden cronológico e indica que deberian ser estudiados en forma interca lada:

19 A! del cap. $10-15$

20 B'' del cap. $28-29$

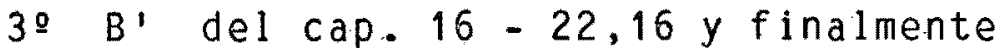

$4 . A^{\prime \prime}$ del cap. $25-27$

II Posterior a estas dos colecciones Salomonicas, sería el Libro III (cap. 22,17 - 24,22), llamado "Colección de Sabios" del que no se puede asegurar una fecha exacta.

II La segunda "Colección de Sabios" (Libro IV cap. 24,2 - 34)) sería posterior a la anterior y de tipo semejante.

IV El libro IV "Palabras de Agur", el libro VII "Prover bios Numéricos" y el libro VIII "Palabras de Lemuel" no ofrecen elementos para una datación probable. Tan to el libro VI como el libro VIII parecen ser prés= tamos extranjeros agregados, el primero como apéndice de la 2a. colección Salomónica, y el segundo a la. Colección de Sabios.

$\checkmark$ El Libro IX, aunque muestra una composición poética mas reciente, el tema parece ser antiguo. Cierra los Proverbios pero no se relaciona con el prólogo; sólo el v. 30 lleva al lector al ambiente Jahvista muy marcado en el Libro I.

VI El Libro I es, sin discusión, el más reciente, proba blemente post-exílico, de la época Persa, s. V a.C. 
En cuanto a la forma, no aparece el distico, salvo en 3,27-30 y en 4,23-27. El tema refleja las preocupaciones religiosas y morales en los sabios. Tratan de armonizar la sabiduría con su Fe Jahvista provocan do una profundización del pensamiento. Parece habe $\bar{r}$ sido también la época en que toda la obra adquirio su forma definitiva (3)

Nuestras observaciones, pues, se basarán en este orden cronológico y a través de ellas seguiremos la suave evolución del pensamiento sapiencial de Israel.

I. En las dos Colecciones Salomónicas más antiguas el pen samiento de los sabios se mantiene dentro de los limi= tes de la sabiduría pragmática, aun cuando no esta ajena la Fe Jahvista. Esta preocupación por Jahveh pareciera ha cerse más marcada a través de los años, al comparar los e $\bar{s}$ critos más tardíos de estas dos colecciones, como son $10 \bar{s}$ del cap. $16-22,16$, con los primeros, es decir, del cap. $10-15$ y del $28-29$; sin embargo lo que en un primer instante aparece claro, se contradice al leer los cap. 25 - 27, designados por Gemser como los más tardios dentro de estas dos colecciones más antiguas. En ellos se men ciona a Jahveh en solo dos oportunidades y en una de ellas, cap. 25,22b aparece como el Dios "Recompensador": "y Jahveh te dará la recompensa"

Ya en esta época los sabios piensan que en el temor de Dios se encuentra la sabiduría; pero aun reconociéndo10 así, le atribuyen además un valor material-terrenal:

"El temor de Jahveh es para vida,

vive satisfecho sin ser visitado por el mal" ( $\mathrm{Pr}$. 19,23)

"El temor de Jahveh prolonga los días

los años de los malos son acortados" (Pr. 10,27)

"Premio de la humildad, el temor de Jahveh

la riqueza, el honor y la vida" (Pr. 22,4).

Pocos son los $M^{e}$ shalim en que aparece Jahveh sin apor tar algo, una recompensa o retribución:

"En todo "lugar, los ojos de Jahveh

observando á los buenos y a los malos" (Pr. 15,3) 
"El rico y el pobre se encueritran a

los dos los hizo Jahveh" (Pr. 22,2)

"El pobre y el opresor se encuentran

Jahveh da la luz a los ojos de ambos". (Pr.29,13) También en $\operatorname{Pr} .16,33$.

En cambio, muchos de ellos nos hablan de Jahveh que retribuye, aun cuando parece que se habla de sentimien tos más profundos y espirituales:

"El que confía en Jahveh prosperará" (Pr.28,25b, cfr. $\operatorname{Pr} .29,25)$

"La bendición de Jahveh es la que enriquece,

y nada le añade el trabajo a que obliga" ( $\mathrm{Pr} .10,22$ )

Desde el cap. 16 al 22,16 Jahveh aparece presente mas que en el resto de las divisiones señaladas por Gemser. En los primeros siete versiculos del cap. 16, hay una uni dad temática en que el sujeto es Dios, supremo acierto, opuesto al hombre falible; se parece a nuestro "El hombre propone y Dios dispone". El vers. 9 es igual a 1-3:

"El corazon del hombre medita su camino pero es Jahveh quien asegura sus pasos" ( $\mathrm{Pr}, 16,9)$

"Al hombre le parecen puros todos sus caminos, pero Jahveh pondera los espiritus" $(\operatorname{Pr} .16,2)$

Nuevamente aparece la presencia de Jahveh en: $\mathrm{Pr} .16$, $11,20,33 ; 17,3,15 ; 18,10,22 ; 19,3,14=18,22 ;$

$19,17,23 ; 20,70,12,22,23,27 ; 21,1-3,30,31 ;-22,2,4,12$; To que podria indicarnos que esta constante presencia de Jahveh estaría marcando una evolucion en el pensamiento sapiencial, pero todavía en el cap。19,17,23;20,22 y 22,4 persiste la idea de Jahveh que aporta una retribu ción.

Se podría pensar, entonces, que en esta época la preo cupación central de los sabios fue la retribución terre nal del individuo. En sentencias breves, de dos miem bros, faciles de recordar, los sabios exponen sus enseñan zas. De la observación del mundo cotidiano ellos hacen una ley universal. Los vemos enseñando ciertas normas, las que cumplidas acarrean felicidad, tranquilidad, triunfo: 
"Mano indolente empobrece,

la mano de los diligentes enriquece" (Pr. 10,4)

"La justicia guarda al integro en su camino,

mas la maldad arruina al pecador" ( $\mathrm{Pr} .13,6)$

"Hombre malo que oprime a los débiles

es como lluvia desvastadora que deja sin pan" ( $\mathrm{Pr} .28,3$ )

"La pereza hunde en el sopor,

el alma indolente pasará hambre" (Pr. 19,15)

"El justo camina en la integridad:

idichosos sus hijos después de éll" (Pr. 20,7)

"Quien va tras la justicia y el amor

hallará vida, justicia y honor"

Ademas podemos citar: $\operatorname{Pr}: 10,2,17 ; 13,13 ; 28,18,27$; $19,5-9 ; 20,13 ; 21,13 ; 22,8 \%$ aquí la retribución se presenta como una consecuencía natural, sin la interven ción divina:

"Quien siembra injusticia cosecha miserias

y la vara de su cólera desaparecerá"

En dos $m^{e}$ shalim de esta colección se hace evidente la mentalidad de los sabios israelitas de esa época; sus consejos giran en torno a las buenas acciones que debe observar el individuo para, de esta manera, obtener una recom pensa que se traduce en exito y bienestar:

"Si tu enemigo tiene hambre, dale de comer,

si tiene sed, dale de beber;

asi amontonas sobre su cabeza brasas

y Jahveh te dară la recompensa" ( $\mathrm{Pr}, 25,21$ y 22)

El sabio enseña que Jahveh es Dios justo:

"De Jahveh son la balanza y los platillos justos, todas las pesas del saco son obra suya" ( $\operatorname{Pr} .16,11$ ) de esta manera el recto siempre será premiado y el malo casti gado:

"Jahveh no permite que el justo pase hambre, pero rechaza la codicia de los malos" (Pr。10,3) 
"Si el justo recibe su recompensa en la tierra, icuánto mâs el pecador y el malo! ( $\mathrm{Pr}$. 11,31)

"Ninguna desgracia le sucede al justo, pero los malos están llenos de misera "( $\mathrm{Pr}, 12,21)$

"A los pecadores los persigue la desgracia, los justos son colmados de dicha" ( $\mathrm{Pr}$. 13,21)

"Quien se apiada del débil, presta a Jahveh

el cual le dará su recompensa" (Pr. 19,17)

A éstos debemos agregar: $\mathrm{Pr} .10,6,7,8 \mathrm{~b}, 11 \mathrm{a}, 17,24$, $25,27-30 ; \quad 11,5,6,8,19,20,21,27,31 ; 12,2,20-22,28$;

$13,6,13,15,17,18,21 ; 14,1,13,26,32 ;-15,4,10,24,29 ;$

$16,4,5,11 ; 17,5,11,13,20 ; \quad 19,5,9,16,17 ; 21,16,21 ; 28$, $10,13,14,26 ; 29,1$

Esta concepción estricta de la justicia de Jahveh, es decir, la recompensa en la tierra, va a ser cuestionada en los libros de Job y Qohêlet.

En todas estas enseñanzas está presente la preocupa ción de los sabios por lo material y por lo terrenal; sē hace evidente en:

"No ames el sueño, para no hacerte pobre;

ten abierto los ojos y te hartarás de pan" $(\operatorname{Pr} .20,13)$

"Se arruina el hombre que ana el placer,

no será rico el aficionado a banquetes" ( $\mathrm{Pr} .21,17)$ Tambiến en: $\operatorname{Pr} .10,4 ; 12,11 ; 14,23,15,6 ; 16,3$.

El sabio se muestra siempre preocupado en la moral del individuo, pero no logra desprenderse del interés por la retribución de estas acciones morales que él acon seja. En el cap. 28 es patente el carácter moralizador que toma la sabiduria y su relación con la ley:

"Mejor es el pobre que camina en su integridad, que el de caminos tortucsos, por mâs rico que sea" $(\operatorname{Pr} .28,6)$

"El que da a los pobres no conocerá la indigencia, para el que se tapa los ojos abundante maldición" ( $\operatorname{Pr} .28,27)$

Este mashal está relacionado con 11,$25 ; 19,17,22,9$; lo que nos permite confirmar que el afán moralizador, en esta época, estaba presente en las colecciones Salomóni- 
cas. Otros versiculos del cap. 28 que demuestran la misma inquietud moral: $\mathrm{Pr} .28,3,5,10,18,22$.

En el cap. 25, y.21 el sabio demuestra idéntica preo cupación por enseñar el amor al projimo, pero en el v.22, al explicar por qué se debe ser bondadoso, nuevamente el fin será la recompensa terrenal:

"Si tu enemigo tiene hambre, dale de comer

si tiene sed, dale de beber;

Asi amontonas sobre su cabeza brasas

y Jahveh te darấ la recompensa" (Pr. 25, 21 y 22)

El sabio hace tambien la oposición entre amor y odio:

"El odio provoca discusiones

el amor cubre todas las faltas" (Pr. 10,12) En Pr. 26, 24-26 y $\operatorname{Pr} .27,5,6,9$ se mantiene esta oposicion.

Otro de los contrastes que usa el sabio en sus conse jos es entre el rico y el pobre:

"La riqueza multiplica los amigos,

pero el pobre de su amigo es separado" (Pr. 19,4)

"Quien se burla de un pobre, ultraja a su Hacedor,

quien se ríe de la desgracia no quedará impune" (Pr. $17,5 \mathrm{cfr}$. 14,31; en el mismo sentido: $\mathrm{Pr}$. 10,15; 14,20,31; $15,15-17$; $16,8,19 ; 17,1,5, ; 18,11 ; 19,4,6,7,22 ; 21,23$; $22,1,2,7,16 ; 28,6,8,11,16 \mathrm{~b}, 20,22,24,27$.

Aunque el sabio de Israel no está preocupado de los asuntos de Estado, aconseja a grandes y reyes, pero, al hacerlo, sus enseñanzas se dirigen al individuo para su exito personal, ya que el triunfo de su gobierno está tam bién concebido como un éxito personal del rey:

"Un rey sentado en el tribunal

disipa con sus ojos todo mal" $(\mathrm{Pr} .20,8)$

"Bondad y lealtad custodian al rey

fundamenta su trono en la bondad" (Pr. 20,28)

"El rey, con la equidad, mantiene el pais,

el hombre exactor lo arruina" (Pr. 29,4) Ademas cfr. Pr. 16, $10,12-15 ; 19,12$ relacionado $\operatorname{con} 20,2 ; 20,26 ; 21,1 ; 29$, 14. 
Los más infimos detalles de la vida diaria están pre sentes en los consejos del sabios para asegurar el éxito$y$ felicidad del individuo:

"El obsequio es un talismann, para el que puede hacerlo;

donde quiera que vaya, tiene éxito. $(\mathrm{Pr}, 17,8)$

"El regalo de un hombre todo se lo allana,

y le lleva hasta la presencia de los grandes" ( $\mathrm{Pr} .18,16)$

"Que otro te alabe y no tu propia boca;

un extraño, que no tus labios" ( $\mathrm{Pr}, 27,2$ )

"No te des importancia ante el rey, no te coloques en el sitio de los grandes;

porque es mejor que te digan: "Suba acá",

que ser humillado delante del príncipe" (Pr. 25,6,7)

Uno de los aspectos que mes interesa al sabio es que el individuo adquiera la sabiduría. Esto es lo primero que hace presente al iniciar sus consejos en el cap. 10,1:

"El hijo sabio es la alegría de su padre,

el hijo necio entristece a su madre" (Pr. 10,1 cfr. 15,20; 17,$25 ; 23,22$. Mantiene esta oposición en cap. 10,$14 ; 12$, 15 y $16 ; 14,33 ; 15,2,5,7,14,20-24 ; 16,16,21,23 ; 17,7$, $16,21,24,25$ y $28 ;$ cap. $18,2,4,7,15 ; 19,13,20 ; 26,1,3=12$; 27, 11,22 ; cap. $29,3,9, \pi 1,15,20$ que $\overline{\text { es }}$ igual a 26,12 .

A traves de todas sus enseñanzas prima su preocupa cion por el hombre sabio. Ya en estas colecciones, que son las más antiguas, el sabio reconoce que solo en el temor de Jahveh se encuentra la sabiduría:

"El temor de Jahveh instruye en sabiduría" ( $\mathrm{Pr} .15,33 a)$

"No hay sabiduría, ni hay prudencia

ni hay consejo, delante de Jahve" ( $\operatorname{Pr}, 21,30)$

Ademas, el sabio indica el camino a seguir para adquirir este saber:

"Escucha el consejo, acoge la correcciôn

para llegar, por fin, a ser sabio" ( $\mathrm{Pr}, 19,20)$ 
Aun cuando al lector le queda muy clara esta preocupación del sabio, y le resulta evidente su interés en que todo individuo adquiera sabiduria, sin embargo, observa, támbiên, que esta preocupación es solo un medio para un fin, y éste es la retribución terrenal:

"Los sabios atesoran conocimiento,

la boca del necio es ruina inmediata" $(\operatorname{Pr}, 10,14)$

"Quien habla sin tino, hiere como espada;

mas là lengua de los sabios cura" ( $\mathrm{Pr}, 12,18)$

"Corona de los sabios es la riqueza,

la necedad de los insensatos es necedad" (Pr。14,24)

"Camino de la vida, * hacia arriba, para el sabio

para que se aparte del seol, que estâ abajo" ( $\mathrm{Pr} .15,24)$

* El camino de la vida, no significa la prolongación de la vida terrestre, opuesta a la muerte, descenso al seol, pues esta noción parece que no formaba parte de la teoría de esa época (4)

"La boca del necio es su ruina,

y sus labios una trampa para su vida" $(\mathrm{Pr}, 18,7)$

"El que confía en su corazón es un necio,

el que anda con sabiduría se salvarâ" (Pr. 28,26) cfr. además en cap。i6,16; 13,3 y 12,13.

En sintesis, en esta época la preocupación de los sa bios se centra en la retribución terrenal del individuo. Se mantienen dentro de un plano humano a pesar de su evidente Fe Jahvista.

II El libro III "Colección de Sabios" desde el cap. 22, 17 al cap. 24,22, tiene muchos contactos con la doc trina de Amenemopé, el sabio egipcio que escribió el año$1000 \mathrm{a} \cdot \mathrm{c} \cdot(4)$

Las enseñanzas del sabio, en esta colección, apuntan sobre todo al valor de la sabiduria. Pr. 22,17-21 es una exhortación al alumno a que escuche sus consejos sabios. 
Inculca en ellos la confianza en Dios, en la que se basa la verdadera sabiduría humana. Mantiene la atención del a lumno sobre la misma materia en: $\mathrm{Pr} .23,9,12,15,19,23$; $24,3-7,9,13$ y 14 :

"Aplica tu corazón a la instrucción, y tus oídos a las palabras de la ciencia" ( $P r .23,12)$

"Escucha, hijo, y serás sábio,

y endereza tu corazón por el camino..." ( $\mathrm{Pr}, 23,19)$

Aun cuando Jahveh está presente: Pr. 22,9,23; 23,17; 24,18; el pensamiento del sabio continúa en un plano hu mano y preocupado de las cosas materiales de la vida: P $\bar{r}$. $23,1-8$ 。

Aunque la preocupación primordial, aquí, parece ser la sabiduría, se hace presente siempre el interês en una retribución:

"Con la sabiduría se construye una casa,

y. con la prudencia se afianza; (Pr.24,3)

"Con la ciencia se llenan los graneros

de todo bien precioso y deseable" (Pr. 24,4)

Siempre que el sabio prohibe o aconseja algo, tras ello viene la motivación:

"No envidie tu corazón a los pecadores,

más bien en el temor de Jahveh permanezca todo el día, $(23,17)$ porque hay un mañana,

y tu esperanza no será aniquilada" $(23,18)$

"No seas de los que se emborrachan de vino,

ni de los que se ahítan de carne, $(23,20)$

porque borracho y glotón se empobrecen

$y$ el sopor se viste de harapos" $(23,21)$

"Come miel, hijo mío, porque es buena.

Panal de miel es dulce a tu paladar. $(24,13)$

Pues sábete que así será la sabiduría para tu alma,

y si la hallas, hay un mañana,

y tu esperanza no será aniquilada" $(24,14)$

Al igual que en las colecciones Salomónicas, el jus to será recompensado y el malo castigado: 
"Que siete veces cae el justo, pero se levanta, mientras los malos se hunden en la desgracia" $(\mathrm{Pr} .24,16)$

"Porque para el malvado no hay un mañana;

la lâmpara de los malos se extinguirán" ( $\mathrm{Pr}$. 24,20)

Como la experiencia de la vida prueba, muchas veces lo contrario, los autores de Job y Qohélet van a cuestionar estas ideas que a ellos no les parecen tan ciertas.

En el cap. 24,17,18 se hace evidente la continuidad en el pensamiento de los sabios de Israel, no se vislum bra todavía una evolución hacia una espiritualización:

"No te alegres por la caida de tu enemigo,

no se goce tu corazón cuando se hunde;

No sea que lo vea Jahveh y le desagrade,

y aparte de él. su ira" (Pr.24,17 y 18)

Aun cuando el sabio da normas de moral, la motivación que lleva a su cumplimiento es la retribución:

"No despojes al débil, porque es débil, y no aplastes al desdichado en la puerta, porque Jahveh defenderá su causa

y despojará de la vida a los despojadores" ( $\mathrm{Pr} .22,22$ y 23)

Poniendo en relieve los problemas que acarrea la fianza, no la recomienda: $\mathrm{Pr} .22,26$, lo que nos presenta las mismas preocupaciones que los sabios en $\mathrm{Pr} .17,18$ y también en $\mathrm{Pr} .6,1$. Demostrando as 1 , que su inquietud por los problemas materiales que se presentan en la vida es de suma importancia.

II En la segunda "Colección de Sabios" desde el cap. 24,23 hasta el vers. 34 , el sabio da a conocer las prohibiciones que impone la ley: $\mathrm{Pr} .24,23-25$. Rechaza la mentira, testimonios falsos y la venganza: $\mathrm{Pr}$. 24,28-29.

Vuelve el sabio a los consejos de bienestar economico en el cap. 24,27 y continúa con ellos en vers. 30-34. En esta altima parte $(v \cdot 30-34)$ el autor, distinto en su estilo, aparece reflexionando sobre lo que él ha visto, ha 
bla en primera persona para aconsejar lo que no debe hacerse si no se quiere caer en la indigencia.

En esta pequeña colección, no se aprecia una evolu ción evidente. Jahveh no se hace presente $y$ el sabio se mantiene en un plano terrenal, apegado a lo material.

IV: Eh el libro VI "Palabras de Agur" que vă desde el cap. 30 v.1 al 14, se aprecia un leve cambio de acti tud en el sabio. Aquí se muestra como un hombre humilde, conocedor de su condición humanás. Confiesa haber intenta do el camino dé la sabiduría, pero no haberlo alcanzado.

Luego demuestra la grandeza de Dios ante la limita ción humana: $\mathrm{Pr} .30 \vee .4-5$; ante Dios, el hombre sólo pue de añadir su reflexión y su oraciôn, a modo de humilde respuesta: $v .6$.

Después de reflexionar sobre la palabra de Dios, el nombre implora humildemente, pidiendo cosas sencillas y fundamentales: la autenticidad al hablar, el pan de cada dia. Reconoce en los dos extremos un peligro: la ex.trema riqueza que lleva a olvidar a Jahveh y la extrema pobreza que puede llevar al robo y a la blasfemia. Los sa bios de las colecciones Salomónicas enseñaban que en eltemor de Dios se encontraba la sabidurla $\mathrm{Pr} .15,33$, pero este sabio, aunque piadoso, dice no haberla adquirido co mo retribución a su piedad. Por el contrario parece pe:dirla como una gracia divina, cuando le implora a Jahveh cosas sericillas: como la autenticidad en el hablar.

En el v. 10 el sabio presenta su primer consejo:

"No calumnies a un siervo ante su amo

no sea que te maldiga $y$ tengas que pagar la pena"

Favorece al humilde, el consejo va acompañado de la motivación acostumbrada por los sabios antes vistos: castigo para el que actúa mel y viceversa. Tenemos, pues, en este versiculo la preocupación por la retribución. Del $v$. 11-14 presenta proverbios como simple constatación, en ellos se contiene un juicio y una enseñanza:

"Hay gente que maldice a su padre y a su madre no bendice, 
gente que se cree pura

y no está limpia de su mancha" ( $\mathrm{Pr}$.30,11 y 12)

$\checkmark$ En el libro VII "Proverbios Numericos" que va desde el cap. 30 v.15 al 33, el sabio presenta además de la maxima, el enigma y la comparacion. Esta breve colec. ción muestra un especial interés en las maravillas de la naturaleza y las costumbres de los animales, tema típicamente sapiencial, apreciado aun en Salmos con influencia sapiencial. El estilo hace atrayente su lectura. Con fra ses enigmáticas y aparentemente misteriosas, el sabio en= seña. Previene en general, contra los mismos males que los sabios más antiguos. Rechaza a la mujer adúltera $v$. 20, al igual que en $\mathrm{Pr}$. 5,1-14. Demuestra también la importancia de la sabiduria: Pr. 30,24-28.

VI En el libro VIII "Palabras de Lemuel" desde el cap. 31 v.l al 9, el sabio se nos presenta como el padre dando consejos a su hijo, ficción literaria muy usada por todos los sabios de oriente. En este caso es la madre quien se encarga de enseñar a su hijo varón y lo prepara a ser rey. Sus consejos son prácticos y su cumplimiento le evitara problemas en la vida. Encontramos en este pequeño 1 ibro elementos conocidos: el tono cordial, entraña ble, como en el cap. 23; los peligros de la bebida y de las mujeres como en la colección 1-9..

En el v. 8 y 9 se preocupa del projimo y le indica como debe comportarse:

"Abre tu boca en favor del mudo, por la causa de todos los abandonados

abre tu boca, juzga con justicia

y defiende la causa del mísero y del pobre" (cap. $31,8,9$, )

Tanto en Proverbios numéricos como en Palabras de Le muel no se hace presente Jahveh. Los consejos se mantienen en un nivel humano-pragmatico. 
VII El libro IX "La perfecta ama de casa" que va desde el cap. 31 v.10 a v.31, es hoy el epilogo de "Pro verbios". Poema alfabético en alabanza de la buena ama de casa. Su forma es más erudita que las anteriores, pero su tema parece antiguo. Es una sabiduría familiar y rural, a la que se ha referido Coutourier en sus estudios cuando compara la sabiduría israelita a la babilónica.

El punto de vista es nuevamente material-económico: buena administración, diligencia y acierto en los negocios; pero también solicitud humana por los empleados y caridad por los pobres. No es la belleza lo que hace una buena ama de casa, por encima de sus cualidades sobresale su temor de Dios ( $v .30)$ o sentido religioso que informa toda su actividad. El fin de este libro es un verdadero himno que entonan maridos e hijos y la voz de sus propias obras: v.28-31). Aunque el recopilador de "Proverbios" parece haber colocado este libro al final por alguna ra$z 6 n$ especial, solo en el $v .30$ encontramos el ambiente Jahvista tan marcado en el Prólogo.

VIII Finalmente, el libro I "Proverbios"que lleva el ti tulo de toda la colección, es la obra más recien = te, posiblemente de la época Persa. En cuanto a la forma empleada aquí por los sabios predomina el discurso didáctico, adoptando, en casi toda la obra, la ficción literaria del padre que enseña a su hijo: Pr. $1,8-19 ; 2,122$;

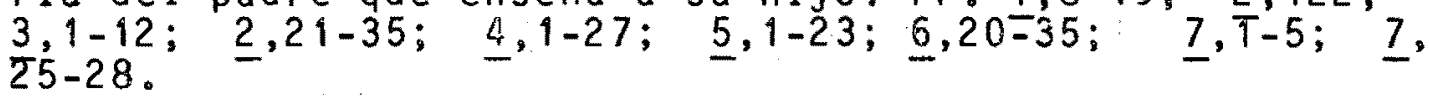

En esta colección se puede apreciar más claramente una evolución en el pensamiento de los sabios de Israel, el que se vuelve mas profundo y espiritual. Las ideas tie nen un sentido menos material y temporal. $\mathrm{Pr} .3,13-18 ; 4$, 4,$9 ; 8,35,36$.

"Pondrá en tu cabeza una diadema de gracia, una espléndida corona será tu regalo" (Pr.4,9)

En el capitulo 1,2-7, el autor introduce su tema:la sabiduria, la que se encuentra en el temor de Jahveh que es a la vez el principio de una sabiduria fundamentalmente religiosa: 
"El temor de Jahveh es el principio de la ciencia;

los necios desprecian la sabiduría y la instrucción" $(1,7)$

"Comienzo de la sabiduría es eltemor de Jahveh,

y la ciencia de los santos es inteligencia" (cap. 9,10)

El temor de Jahveh es una mezcla de amor, sumisión y confianza. En el prólogo, el sabio es un padre que aconse ja a su hijo ( $v$. 8-19) que no se deje arrastrar y corrom = per por los pecadores, porque, si así fuera, sólo recibi ria castigos. Se mantiene el pensamiento de la retribu ción para el justo y bueno, y el castigo para el malvado: v. 18-19.

En el versículo 2-33 del cap. I el sabio se vale de la alegoría y presenta a la sabiduría personificada. Esta habla en las calles a la manera de los profetas, y exhorta a los nombres a actuar con sabiduría. Promete castigo al que no la escuche y felicidad al que la siga.

$\operatorname{Pr}$ 1,24-32, expone todo el castigo que llegara que ha despreciado sus consejos. En $v_{0} 33$ demuestra que el que actúa con sabiduría no encontrará la desgracia.

En el capitulo 2 continúa dando consejos como un padre a su hijo. Si se entiende a la sabiduria y se acatan sus consejos no hay peligro, pues cuando logra entrar la sabiduría en el corazón, ésta aparta del mal camino:

"Cuando entre la sabiduría en tu corazón

y la ciencia sea dulce para tu alma

velará sobre ti la reflexión

y la prudencia te guardará" (Pr。2,10,11)

Se insiste en la recompensa para el recto y justo y en el castigo para el malo:

"Porque los rectos habitarán la tierra

y los integros se mantendrán en ella;

pero los malos serán cercenados de la tierra,

se arrancará de ella a los desleales" ( $\mathrm{Pr}, 2,21$ y 22)

En capitulo 3 contináan los consejos paternales. El cumplimiento de las lecciones del sabio acarrea larga vida y bienestar: $\operatorname{Pr}, 3,1-2$. La confianza en Jahveh, el temor 
de Jahveh y su honra significan felicidad: v. 5-10. Hasta aqui el sabio se mantiene en un plano terrenal-pragmático. En el v. 13-18 el sabio se torna mas espiritual y asegura que poseer la sabiduría es más valioso que cualquier riqueza material: $\operatorname{Pr} .3,13-15$; es árbol de vida y felici dad: V.18. El V. 19 y 20 se asemeja a cap. 8,22-31, don de se presenta a la sabiduria como la primogénita y creadora. En el vo 21-26 se hace más evidente la evolución en el pensamiento sapiencial. Ya no está tan apegado a lo concreto y práctico. La motivación a la observación de un consejo es mas espiritual:

"Hijo mio, guarda la prudencia y la reflexión, no se aparten nunca de tus ojos:

serán vida para tu alma

y adorno para tu cuello. ( $\mathrm{Pr}, 3,21$ y 22)

La retribución, al cumplimiento de los consejos, es ahora tranquilidad de espiritu: $v, 23-26$.

"Porque Jahveh será tu tranquilidad

y guardara tu pie de caer en el cepo" ( $v .26)$

Del vers. 24 al 33 el sabio enumera una serie de cosas que no se debe hacer. Quien observa estos mandatos gozars de intimidad con Jahveh:

"Porque Jahveh abomina a los perversos, pero su intimidad la tiene con los rectos" ( $\mathrm{Pr}, 3,32)$

Aqui también se hace evidente la recompensa mas espi ritual, ya no es el apego a la riqueza lo que preocupa aT sabio, como en la época de las colecciones Salomónicas, sino lo que se recibirá a cambio de una buena acción será un entendimiento con Jahveh. Se hace presente en este cap. 3 la retribución del justo y el castigo del malo al igual que en todas las antiguas colecciones, problema tan discutido por los autores de Job y Qohelet:

"La maldición de Jahveh en la casa del malvado,

en cambio bendice la mansión del justo" (Pr.3,33 cfr. 34 y 35)

- En el capitulo 4, el sabio continua exhortando a su hijo a cumplir sus consejos. Dice en el v. 7b: 
"a costa de todos tus bienes adquiere la inteligencia", la re compensa a ello es la adquisición de un diadema de gracia v: 9. En general en todo el capítulo es clara la evolu. cion del pensamiento sapiencial: $\operatorname{Pr} .4,18,19,23$ :

"La senda de los justos es como la luz del alba, que va en aumento hasta llegar a pleno día" $(4,18)$

"Pero el camino de los malos es como tinieblas no saben dónde han tropezado" $(4,19)$

"Por encima de todo cuidado, guarda tu corazón, porque de él brotan las fuentes de la vida. $(4,23)$

- En el capitulo 5 el sabio apela nuevamente a su hijo y le aconseja alejarse de la mujer extraña; en ella seria posible ver la personificación de la necedad en contraposición a la sabiduría, a la que es imprescindible escuchar $y$ seguir. La esposa legitima podria representar simbolicamente a la sabiduria personificada.

- En el capitulo 6 el sabio se muestra, al igual que en colecciones anteriores, enemigo de la fianza: Pr.6, 1-5 igual a 11,$15 ; 17,18 ; 20,16 ; 27,13 ; 22,26-27$. También habla del perezoso, preocupacion que tuvieron, en la misma forma, los sabios tradicionales: $\mathrm{Pr} .20,4,13 ; 22,12$; 24,$3034 ; 30,24-25$. En cap. 6, 16-19, enumera una serie de siete acciones que aborrece Jahveh; nuevamente previene contra la mujer adúltera v.24-35. En este capitulo el sabio se acerca, en sus preocupaciones mas practicas y te rrenales, a los sabios de antaño.

- En el capitulo 7 se mantiene la ficción del padre aconsejando al hijo y lo exhorta a escuchar sus sabias ense ñanzas v.1-4; en el v.5 vuelve el autor a prevenir con = tra la mujer ajena. En el $v .6$ el sabio empieza.a relatar sus experiencias en la vida, en primera persona; se parece al estilo adoptado en la "segunda colección de Sabio.s", donde en el cap. 24 v.3-34 el autor reflexiona sobre sus experiencias y las enseña. Desde el v. 6 al 27 el sabio se dedica a aconsejar contra la mujer ajena. 
- En el capitulo 8 se nos aparece la sabiduria personificada. Su figura contrasta claramente con la "mujer extranjera" presentada a través de todo el cap. 7. Al revés de su antagonista, la sabiduría habla en páblico, de día, en voz alta: $v$ 。 1-3. En cambio en "la mujer extranjera", que podría personificar a la necedad, se presenta al oscurecer, cap. $7 v .9$, habla a escondidas: $7 v .12 b$, es salamera y falsa: 7 v. 16-18.

La sabiduría se presenta también con el nombre de Prudencia:

"¿No esta llamando la Sabiduria?

y la Prudencia, ino alza su voz? ( $\mathrm{Pr}, 8,1)$

y se ofrece para salvar a todos los nombres, ya que la sa biduria es más apetecible que cualquier otra cosa: $\mathrm{Pr} .8$, 4-11.

"Porque mejor es la sabiduria que las piedras preciosas, ninguna cosa apetecible se le puede igualar" $(8,11)$

Del y。12-21 la sabiduría se autoelogia. Es un verda dero himno a si misma. Muestra sus cualidades y al mismō tiempo excluye en ella vicios como soberbia y orgullo. Ex presa que ella es mas valiosa que el oro puro y la platā acrisolada: v. 19.

En el vers. 17 dice:

"Yo amo a los que me aman

y los que me buscan me encontrarán"

La sabiduría aquí, señala el camino más fácil para llegar a ella, demostrando en él una mayor espiritualidad, quedando así demostrado también que el pensamiento de los sabios se hace más profundo. Desde el v. 22 al 31, la sa biduría se presenta como la primogénita. Esta es unasección cósmica, referida a la creación. La sabiduría se muestra más allá de los tiempos y abarcando con su presen cia los espacios: $y_{\circ} 23,30 a$; numerosas veces el autor menciona, con variaciones, la palabra "antes" que es representación poética, ya que antes de la creación no hay tiempo. Se declara engendrada como primogénita del Señor: 
"Jahveh me creo, primicia de su camino, antes que sus obras más antiguas" $(8,22)$

Desde el v. 32-36 es apreciable la sabiduría en una esfera religiosa. La sabiduria se comunica con los hom bres a través de la palabra y al hacerlo les trae vida y el favor de Jahveh:

"Porque el que me halla, ha hallado la vida,

ha logrado el favor de Jahveh". $(8,35)$

En estos versículos estamos ya dentro de un plano to talmente espiritual y religioso, la sabiduria se presenta aquí como el Fin Final. No es, ahora, un medio para obte ner un bienestar material. como lo fue antaño;"

"Adquirir sabiduria, cuắnto mejor que el oro;

adquirir inteligencia es preferible a la plata" (Pr. 16, 16) cfr. 14,$24 ; 18,7$.

El vers. 36 completa la idea del v. 35 :

"Pero el que me ofende, hace daño a su alma;

todos los que me odian, aman la muerte"

Nuevamente el cambio es notable, la pérdida que se sufre ahora es una pérdida espiritual y no como en los tiempos antiguos en que significaba siempre una ruina material:

"La boca del necio es su ruina,

y sus labios una trampa para la vida" $(\operatorname{Pr}, 18,7)$

- El capitulo 9 contiene dos invitaciones de la sabiduría $v$. 1-6 y de la necedad $v$. 13-18, interrumpidos por un par de proverbios $v .7-9 ; 11-12$ y el lema de este libro en el v. 10, el que aparece tanto al comienzo de esta colección cap. 1,7, como al final de la misma: 9, 10.

"Comienzo de la sabiduría es el temor de Jahveh, y la ciencia de los santos es inteligencia". 


\section{CONCLUSION}

Hemos seguido en nuestro estudio, un analisis cronolo gico del pensamiento sapiencial de Israel, en el libro de los Proverbios, centrando nuestra atención en las inquietudes que motivaron al sabio y en lo que ellos esperaban de la vida. De esta forma, hemos observado un progreso doctrinal. En sus comienzos, el pensamiento de los sabios de Israel equivale al pensamiento generalizado en to do el antiguo oriente, donde predomina un tono de sabidu= ria humana y profana. Sin embargo, con el correr del tiempo, su doctrina se torna más espiritual y más profunda. En los escritos mas recientes, se acercan mas al pen sar de los demas escritores bíblicos, aqui examinados, $\bar{y}$ se alejan un tanto del resto de la sabiduria oriental, y esto, sobre todo, por la fe Jahvista que predomina en las Ulitimas colecciones.

Ahora bien, considerando estos dos factores anotados ¿como concibieron el exito estos sabios?

En las colecciones mas antiguas, su preocupación esta centrada en la retribución material, el exito para ellos significa bienestar, riquezas, dicha, familia-hijos. ¿como se obtiene todo esto? El sabio dice que la fuente de todas estas bondades de la sabiduria es el temor de Dios: 15,$16 ; 16,6$.

"El temor de Jahveh intruye en sabiduria" ( $\mathrm{Pr} .15,33) \mathrm{cfr}$. y sólo en Jahveh se debe confiar:

"confía en Jahveh, que te salvará" (Pr. 20, 22b)

"el que confla en Jahveh está seguro" ( $\mathrm{Pr}, 29,25 \mathrm{~b})$

La sabiduria es, pues, por una parte fuente de bien estar material y felicidad:

"Corona de los sabios es la riqueza,

la necedad de los insensatos es necedad" (Pr. 14,24)

"Los sabios atesoran conocimientos

la boca del necio es ruina inmediata" (Pr. 10,14) 
y por otra parte significa cumplir las normas sapienciales, significa buenas acciones:

"El que da a les pobres no conocerá la indigencia, para el que se tapa los ojos abundante maldición" (Pr.82,27)

"Si tu enemigo tiene hambre, dale de comer si tiene sed, dale de beber:

así amontonas sobre su cabeza brasas

y Jahveh te dará la recompensa" ( $\mathrm{Pr} .25,21$ y 22)

10 que acarrea necesariamente bienestar y éxito terrenal.

Luego, en sus inicios la sabiduria Israelita se nos presenta en un plano humano en el que no esta ajena la fe Jahvista: $\operatorname{Pr} .10,27 ; 22,4 ;$ pero el sabio siempre es pera de su Fe, de su sabiduría y de sus buenas acciones una recompensa que se traduce siempre en algo practico y concreto:

"El que confía en Jahveh prosperara" ( $\mathrm{Pr}, 28,25 \mathrm{~b})$

"La bendición de Jahveh es la que enriquece" ( $\mathrm{Pr} .10$, 22 a)

"La boca del necio es su ruina" $(\operatorname{Pr} .18,7)(16,16)$

"Quien va tras la justicia y el amor

hallará vida, justicia y honor:" (Pr. 21,21)

Sin embargo, en la alltima colección, es decir, el li bro I, el pensamiento de los sabios evoluciona: Pr: 3,2326 y en el cap. 8. es más claro aún; el cambio se hace ya evidente en el cap. 3,32b.

"Porque Jahveh abomina a los perversos

pero su intimidad la tiene con los rectos"

El sabio se muestra ahora más espiritual, su preocupación ya no se centra tanto en la recompensa material, la intimidad con Jahveh le es suficiente. Más tarde en el cap. 8 v. 35 encuentran en la sabiduria la máxima recompensa, ella es, en esta etapa, una retribución en sí misma, y no un medio para obtener otro bienestar: Llegara el momento en que los pensadores de Israel harán la criti ca de esta "teoría!" (Qohélet, Job, p.ej.) 
Estos sabios, al igual que sus colegas de antaño, encuentran la sabiduria en el temor de Dios: $\mathrm{Pr} .1,7$; 9,10 y el tener la sabiduria significa tener el favor de Jahveh:

"Porque el que me halla, ha hallado la vida, ha logrado el favor de Jahveh" $(\mathrm{Pr} .8,35)$

Es asi como después de haber partido de una sabiduria que centraba su interes en una retribución material, concreta traducida en un éxito terrenal, nos en contramos ahora, en las altimas colecciones, con un pensamiento que culmina en una preocupación absoluta mente espiritual y religiosa. Se ama a Dios y se actáa bien sólo esperando a cambio de ello, la intimidad con Dios y el favor de Jahveh: $\mathrm{Pr}, 3,32 \mathrm{~b}$ y $\mathrm{Pr}$. 8,35b. 


\section{BIBLIOGRAFIA}

1. BIBLIA DE JERUSALEN - Nueva Edición - Desclée de Brou wer, Bilbao, 1975.

2. LE livre des PROVERBES - BarUCQ, André. S.D.B. J. Gabalda é $C_{0}$, éditeurs, París, 1954.

3. PROVERBIOS Y ECLESIASTICO - Traducción de Luis Alonso Schöckel - Ed. Cristiandad, Madrid, 1958.

4. APUNTES SEMINARIO - Profesor Sr. Jaime MORENo. Segundo semestre - 1978 .

NOTAS

(1) André BARUCQ S.D.B. Librairie Lecoffre, J. Gabalda et C., êditeurs, Paris - 1964.

(2) Biblia de Jerusalén, Bilbao - 1975. BARUCQ; André, Paris - 1964. Apuntes Seminario Biblico - Profesor Sr. Jaime MORENO.

(3) LE LiVRe des PROVERBES - BarucQ, André, Paris - 1964. PROVERBIOS Y ECLESIASTICO - SCHOCKEL, LUiS AlOnSO, Ma drid, 1968.

BIBLIA DE JERUSALEN, Bilbao - 1975.

(4) BIBLIA DE JERUSALEN, Bilbao - 1975. 